\title{
TRAÇOS DO PENSAR FILOSÓFICO ${ }^{1}$
}

\author{
José Barata-Moura
}

(Universidade de Lisboa)

\section{Intróito}

Agradeço o lisonjeiro convite para esta oração. Sinto-me especialmente honrado, por ele partir do Departamento a que pertenço.

Nos termos da encomenda, é suposto que a minha fala assuma o formato de uma conferência inaugural das actividades de um ano lectivo. Para gente que está a começar. Para resistentes que continuam. Para caminheiros em troço de (transitória) saída.

Gostaria de ser capaz de imprimir ao meu discurso a forma melodiosa - pese embora as dissonâncias no conteúdo - de uma verdadeira abertura festiva.

Porque há viagens em início. Labores em aprofundamento. Excursões em fase de reconfiguração. E sobretudo porque a alegria - mesmo no meio das dificuldades (a que não dá instantâneo sumiço) - é um apanágio condimental da festa do pensar.

Olhando para mim - e suspeitando do que, sem presumíveis traições, a postura e o aspecto traduzem quanto a prazos de validade -, direis, com desencantadora razão, que vos canto à beira do final de uma jornada.

A observação está, no facto, correcta. O meu contacto - directo, e

${ }^{1}$ Palestra realizada na Faculdade de Letras da Universidade de Lisboa, em 6 de Outubro de 2014. 
quotidiano - com a filosofia já ultrapassou a fronteira do primeiro meio século.

Aprendi muito. Ainda sei pouco. Duvido que tenha ensinado grande coisa.

Prossigo - sem fingimento do prazer - nas minhas buscas.

Não esperem, por isso, nem um elogio tenso da velhice (tantas vezes, apenas um desastrado encómio tanso da loucura). Nem uma revelação fumegante dos mistérios do negócio (já que, por feitio, sou avesso aos ócios da liturgia oracular). Nem cascatas de sabença em testamento aos vindouros (por defeito manifesto de massa líquida a jorrar do fontanário, e por ausência notória de herdeiros em bicha com o cantarinho à bica).

Procurarei tão-só dar-vos conta de umas coisas que me foram acontecendo ao pensar. Que, para mim, têm valor de uso. Mas que só na circulação da troca com a vossa experiência pensada poderão realizar algum benefício em efectivo.

Avancemos, então.

\section{Uma coutada?}

A primeira nota pode trazer desconsolo às hostes do eremitério. Mormente, às almas devotas, mais propensas ao culto da santa em recinto fechado.

O pensar não é uma coutada exclusiva. Com acesso reservado. Aonde somente aos sócios do «Clube da Filosofia», e com a quotização em ordem, é permitido andar à caça. Ainda que Nicolau de Cusa - manejando a metáfora venatória com calejado ofício - tenha chamado aos filósofos: «caçadores de sabedoria» (venatores sapientiae) ${ }^{2}$.

O matagal para as expedições cinegéticas desta índole é campina aberta. $\mathrm{O}$ porte de arma requer jeito, mas não carece de licença. E os praticantes da função extravasam largamente o rol dos que têm ficha cadastrada no grémio.

$\mathrm{Na}$ diferença de todas as diferências, os cientistas pensam. Os poetas pensam. O engenheiro pensa. Os artistas pensam. O homem comum pensa. As crianças... pensam.

Não obstante, ocorre que é própria dos filósofos uma ocupação com o pensar.

Para além, de existirem, porventura, traços característicos do modo filosófico de se embrenhar pelo pensamento. Os quais - por certo, e documentadamente - se vêm a plasmar numa multidão de doutrinas,

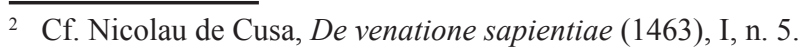


disparam por sendeiros metodológicos diversos, reflectem imagens distintas do mundo e da vida, aportam a balcões de perspectiva e a posicionamentos existenciais diferenciados.

O que acarreta (compreensível) distúrbio. Mas o ramalhete das perturbações não está concluso. Outros vectores acrescem, sem constituirem excrescência.

Lembro mais duas ocasionalidades, indutoras de desconforto acrescido.

É uma lástima surpreender - constando, porém, da caderneta das infelicidades com registo - esporádicas situações de desgraça em que diplomados, profissionais da filosofia com certidão carimbada, multiplicam os sintomas de não possuir um vislumbre sequer do que seja propriamente a experiência do pensar. De facto, eles «tiraram» o curso. Tiraram, porque não fizeram eles próprios o percurso. E, quando lhes toca a malfadada hora de ministrar ensino, debitam fraseados, esquemas, definições. Mas, qual é o fundo genuíno de que estas criaturas dispõem para trans-mitir recheio vitalizado aos conteúdos que a moldura de um nome abstruso agasalha? Vá-se lá saber...

O carrego da condição de «filosofantes» - a que, na forma tentada, procuramos fazer jus - pesa, no entanto, ainda umas arrobas mais.

Seguramente que se podem expôr em calhamaços, e despejar nas aulas, catervas de opiniões dos filósofos mais ilustres. De um passado longínquo hauridas (a golpe de serões de queima da pestana), ou acabadas de encontrar à esquina (nalgum cavaqueio de botequim em voga).

Exposição e despejo podem revestir até indumento e modalidades de excelência. No virtuosismo da oratória. $\mathrm{Na}$ apanha do interesse. Nas funduras, no rigor, na clareza, com que se escalpelizam os meandros e encrencas de um dado argumento.

E, apesar de tudo, podemos ficar pelo pórtico, sem verdadeiramente entrar.

Somos capazes de descrever correctamente o que lá está. Mas nós não pensamos lá. Somos capazes de enunciar sentidos à «matéria». Mas, para nós, é um madeiro que não faz sentido. Conhecemos os filosofemas. Mas não investimos pelo filosofar.

Terrível exigência a deste nosso mester. Sem exercício efectivo do pensar, não há filosofia. Haverá movimentação de uns vultos pelo palco, mas falta a festa. 


\section{O marco do pensar}

Pensando, estamos junto de nós mesmos. No aconchego da nossa casinha.

É o momento subjectivo da «vivência» do pensar.

Um território endógeno ao qual Ortega y Gasset tantas vezes aludiu, mesmo se para lhe dependurar uma «circunstancialidade» (representada) de que nos incumbiria o resgate da perdição no anonimato: «Eu sou eu e a

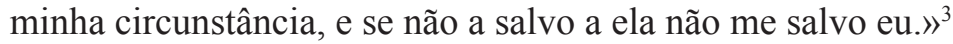

O momento subjectivo do pensar afeiçoa-nos - até na cartesiana dúvida - a uma presença com-partida da intimidade.

Todavia - mesmo no dilacerado das cisões, e no dividido das hesitações -, nós pensamos o real. Assentados, mas não sentados, na deveniência concreta do ser - que habitamos, e onde vamos sendo. Numa acidentada, mas constante, dialogia metabólica com ele. No horizonte prático de um viver que se prolonga.

Pensamos no real. Mas, acaso, o mais importante é que pensamos de dentro do real, e a partir dele.

Pensamos de dentro do real, quando o descrevemos em conto, e o medimos com a régua. Quando intentamos compreendê-lo. Quando procuramos orientação no mundo. Inclusivamente, no nosso mundo dos afectos (que não é só um quartito esconso na cave monadológica: sem janelas ${ }^{4}$, e com pouco ar).

3 «Yo soy yo y mi circunstancia, y si no la salvo a ella no me salvo yo.», José Ortega y Gasset, Meditaciones del Quijote (1914), Lector...; ed. Julián Marías, Madrid, Ediciones Cátedra, 19843, p. 77. É, pois, na bacia destes mares interiores que as operações de busca e salvamento decorrem.

4 A expressão é de Leibniz. E, a partir dela (e do património que condensa), muitas outras peregrinações ao íntimo foram tentadas.

Segundo a metafísica leibniziana, «as Mónadas não têm de todo janelas» (les Monades n'ont point de fenêtres), porque «cada Mónada é um espelho vivo, ou dotado de acção interna, representativo do universo, segundo o ponto de vista dela, e tão regulado quanto o próprio universo» - «chaque Monade est un miroir vivant, ou doué d'action interne, representatif de l'univers, suivant son point de veue, et aussi reglé que l'univers luy même». Cf. Gottfried Wilhelm Leibniz, Monadologie (1712-1714), 7, e Principes de la Nature et de la Grace, fondés en raison (1712-1714), 3; Die philosophischen Schriften, ed. Carl Immanuel Gerhardt (doravante: PS), reprod. Hildesheim, Georg Olms Verlagsbuchhandlung, 1965, vol. 6, respectivamente, pp. 607 e 599.

Como fundamento e instância reguladora deste harmonismo, emerge uma criativa actuosidade teogénica. Porque «Deus é tudo em todos» (Dieu est tout en tous), «somente Deus faz a ligação ou a comunicação das substâncias, e é por ele que os fenómenos de uns se encontram e se acordam com os de outros, e que, por consequência, há realidade nas nossas percepções» - «Dieu seul fait la liaison ou la communication des substances, et c'est par luy que les phenomenes des uns se rencontrent et s'accordent avec ceux d' autres, et par consequent qu'il y a de la realité dans nos perceptions». Cf. Leibniz, 
Pensamos ainda de dentro do real, quando nos enganamos. Quando distorcemos. Quando mentimos. Quando soltamos as rédeas no galope à imaginação. Quando trans-gredimos a positividade rigidificada do existente, assestando o rumo a outras andanças e a figuras transformadas do ser.

Continuamos a pensar o real, e de dentro do real, mesmo quando num enredo de aflições (mais no angustiado sofridas, do que com correcção no olhar em clave activa enfrentadas) - pretendemos converter a cogitação num sofisticado aparelho de fuga para os subúrbios desempestados de uma «realidade» pestilenta.

O nosso pensar está efectivamente montado sobre um viver. E o pensar - no seu modo, modelação, e modulações - não é de todo estranho à qualidade, ao espessor, à densidade, do nosso viver.

A intenção originária, e manifestada, era outra. Tratava-se de, em nome da ética, despedir o materialismo - um desígnio que não corresponde de maneira nenhuma nem ao embasamento, nem à abordagem do tema, a que eu procedo. No entanto, é para o significante desta articulação com o plano recuado do viver que um conhecido brocardo de Fichte acaba por nos conduzir: «Aquilo que se escolhe como filosofia depende, por conseguinte, de aquilo que se é como um ser humano» ${ }^{5}$.

Já sem aligeiradas operações de contrabando hermenêutico e de forçosa inflexão no sentido, caberia evocar, sim, pelos assentamentos que clarifica, uma bela e ajustada expressão de Marx, que musicalmente soa muito bem no alemão, mas que vale a pena meditar não apenas pelos seus atributos estéticos: «a consciência (das Bewußtsein) é «o ser consciente» (der bewußte Sein), e «o ser dos humanos» (das Sein der Menschen) é o seu «processo [efectivamente] real de vida» (wirklicher Lebensproze $\beta)^{6}$.

Discours de Métaphysique (1686), § 32; PS, vol. 4, respectivamente, pp. 457 e 458.

A via da harmonização monadológica na constituição transcendental intersubjectiva do mundo objectivo teve também outras derivas, e cultores. Cf., por exemplo, Edmund Husserl, Cartesianische Meditationen. Eine Einleitung in die Phänomenologie (1929), § 49; Gesammelte Werke (Husserliana), ed. Hermann Leo Van Breda, Den Haag, Martinus Nijhoff, 19732, vol. I, pp. 137-138.

5 «Was für eine Philosophie man wähle, hängt sonach davon ab, was man für ein Mensch ist», Johann Gottlieb Fichte, Erste Einleitung in die Wissenschaftslehre (1797), 5; Werke, ed. Immanuel Hermann Fichte, reprod. Berlin, Walter de Gruyter \& Co., 1971, vol. I, p. 434.

6 Cf. Karl Marx - Friedrich Engels, Die deutsche Ideologie. Kritik der neuesten deutschen Philosophie in ihren Repräsentanten Feuerbach, B. Bauer und Stirner, und des deutschen Sozialismus in seinen verschiedenen Propheten (1845-1846), I, A; Marx-Engels Werke, ed. IML (doravante: MEW), Berlin, Dietz Verlag, 19694, vol. 3, p. 26. 
Acresce que, no plano ontológico, o ser não se reduz ao momento imediato de cada existência isolada, enquanto elemento atómico e unidade discreta. A historicidade empapa - de movimento, de mudança, de transformação - o corpo mesmo de aquilo que (tantas vezes, para o fixar) chamamos o real.

Identidade não é mesmidade. A identidade é sempre uma unidade em processo, que entrelaça e reconfigura a mediação do «mesmo» e do «outro».

\section{Relacionalidade}

Por outra parte, o pensar requer e mobiliza uma protagonização.

Kant converteu o assumir desta atitude num emblema da Aufklärung?. Em divisa daquele programa de Luzes - procuradas, e acendidas - que há-de alicerçar-se num exercício da autonomia. «Pensar por si mesmo» (Selbstdenken). Pondo a uso a razão. Submetendo tudo ao tribunal de uma dilucidação crítica reflexiva. Desinibindo uma criatividade própria. Soltando-se da tutela cómoda e das andadeiras que amparam uma menoridade heterónoma. Para abrir o passo à liberdade de se dar um destino.

O comentário sarcástico de Hegel é contundente, pela defenestração de bordões romantizados a que, sem cerimónia, procede: «"O meu pensar próprio" é propriamente um pleonasmo. Cada um tem que pensar por si [mesmo]; ninguém pode pensar pelo outro.. ${ }^{8}$

Há, sem dúvida, um momento subjectivo que é imprescindível na activação do pensar. É constitutivamente intrínseco ao desempenho da própria função. Uma sua não comparência eventual determina a nulidade daquilo mesmo que pretendesse subir à cena disfarçado de pensar.

Esta necessária condição interna, todavia, não é suficiente. Porque nos deixa remetidos, e encapsulados, num reduto abstracto, isolado, ao qual falta a concreção das determinações e dos seus desenvolvimentos.

O pensar é, todo ele, um acto de entregas à relacionalidade.

Pensamos em relação com o mundo. Pensamos desde, e na

7 Cf. Immanuel Kant, Beantwortung der Frage: Was ist Aufklärung? (1784); Gesammelte Schriften, ed. Königlich Preussische Akademie der Wissenschaften (doravante: Ak.), Berlin, Georg Reimer, 1923, vol. VIII, pp. 53-61.

8 «"Mein eigenes Denken" ist eigentlich ein Pleonasmus. Jeder muß für sich denken; es kann keiner für den anderen denken.», Georg Wilhelm Friedrich Hegel, Vorlesungen über die Geschichte der Philosophie, Einleitung, B, 2, a; Theorie Werkausgabe, red. Eva Moldenhauer e Karl Markus Michel (doravante: TW), Frankfurt am Main, Suhrkamp Verlag, 1971, vol. 18, p. 80. 
respiração de, uma cultura. Pensamos e vivemos sempre em comunidade - mesmo quando dela estamos fisicamente apartados, ou quando apetecemos apartar-nos do seu convívio directo. $\mathrm{O}$ nosso singularismo, a nossa individualidade - aspectos constituídos que não são para votar ao menosprezo -, somente ganham efectiva estação no incontornável contorno de uma trama complexa e lábil de relacionamentos.

O próprio Kant - ao seu jeito idealista transcendental, um pensador profundo da realidade - não deixou, aliás, de conferir o devido destaque a esta vertente. Ouvimos, de ordinário, dizer que ninguém nos pode retirar «a liberdade de pensar» (die Freiheit zu denken). Mas, logo Kant se apressa a contrapôr: «quanto haveríamos nós de pensar, e com que correcção [Richtigkeit], se não pensássemos, de alguma maneira [gleichsam], em comunidade com outros [in Gemeinschaft mit andern], com os quais partilhamos [mitteilen] os nossos pensamentos, e que partilham os deles connosco? $»^{9}$

Com justificada cabida neste capítulo - apesar da compreensão menos justa de Hegel a que empresta a voz -, seria de não esquecer aqui um celebrado aforismo de Feuerbach: "A verdadeira dialéctica não é nenhum monólogo [kein Monolog] do pensador solitário [einsamer Denker] consigo mesmo; ela é um diálogo [ein Dialog] entre Eu e Tu [zwischen Ich und Du].» ${ }^{10}$

No patamar intersubjectivo da descoberta conjunta, e da feitura, do mundo e da vida, esta observação de Feuerbach tem, pela certa, o seu fundamento. Não obstante, é indispensável não perder também de vista todas as demais dialécticas (subjacentes, e adjacentes) que, conferindo arcaboiço aos tabuleiros da comunicação e modelando-lhe o viso dos conteúdos, enterram o seu raizame na materialidade - histórica e humanamente mediada - do ser.

Seria, de resto, um interessante assunto mais para a reflexão filosófica.

9 «wie viel und mit welcher Richtigkeit würden wir wohl denken, wenn wir nicht gleichsam in Gemeinschaft mit andern, denen wir unsere und die uns ihre Gedanken mitteilen, dächten!», Kant, Was heißt: sich im Denken orientieren? (1786); Ak., vol. VIII, p. 144.

10 «Die wahre Dialektik ist kein Monolog des einsamen Denkers mit sich selbst, sie ist ein Dialog zwischen Ich und Du.», Ludwig Feuerbach, Grundsätze der Philosophie der Zukunft (1843), § 64; Gesammelte Werke, ed. Werner Schuffenhauer, Berlin, Akademie-Verlag, 1982, vol. 9, p. 339. 


\section{Uns traços}

Tendo por telão de fundo esta paisagem ontológica, e prosseguindo neste roteiro a nossa caminhada, vale, então, perguntar:

Que traços característicos, muito genéricos, poderíamos nós discernir no pensar filosófico?

Vou cingir-me a uns quantos apontamentos.

Esqueléticos na ossatura, e telegráficos no percutir da tecla.

A crítica. Um rastilho muito falado, que tem o infectuoso costume de se arrastar mais pelas bocas sem consistência (mas com sonoro alarido), do que de propriamente acender a mecha ao detonar da meditação.

Criticar não é dizer-mal; é procurar ver bem. Tão-pouco criticar é contrapôr, de um modo abstracto e mecânico, enunciações que entre si se excluem. A fim de preparar, não raro, uma saída airosa para o elegante salão dos cepticismos.

$\mathrm{O}$ assunto em causa é outro. A crítica é um exame: um fazer passar pelos crivos da racionalidade, e do discernimento, tudo aquilo que imediatamente se nos apresenta - ou que nos oferecem de presente na bandeja - como uma datidade inquestionável.

Por isso, o pensar filosófico - descendo uns lanços de escada no trabalho - aponta também a uma demanda de fundamentação.

Não, como entono cadenciado de uma ladainha de «motivos»e de «motivações» justificantes. Não, com o sorrateiro propósito de erigir solenemente «A Filosofia» em pedra angular inamovível de todo o edifício da ciência universal. Mas, como porfiada linha de uma busca dos supostos que suportam e estruturam - inclusivamente, na sua dinâmica - tudo aquilo por cuja inteligibilidade importa que se pergunte.

E, para isso, há que cuidar de um estabelecimento correcto dos problemas.

A labuta do pensar não visa simplesmente as respostas que, em prémio, hão-de obter-se. Precisa de madrugar. Começa mais cedo. Pela elaboração dos questionários.

As «soluções» não caem do céu. De paraquedas. Por inspiração funda de alguma corrente de ar benfazeja. Rodopiando no espirro incandescente de uma revoada de luz, ou no piar de um passarinho. As vias resolutórias engendram-se, surgem, e transpiram, de dentro de uma problemática que lhes define um horizonte.

Confirma-se que os filósofos parecem ter predilecção pelo accionamento de uma estranha maquineta que dá pelo nome sugestivo de «complicómetro». Mas não é porque eles estejam possuídos por uma indebelável mania de ensarilhar os lotes.

O sarilho está metido no próprio enredamento das coisas. E para desenvencilhar é preciso trazê-lo à mastigação do pensamento. 
Sem um ensaio de penetração inteligente na contraditoriedade complexa do real - nas suas distintas camadas, articulações, e movimentos -, permanecemos apenas pela água rala de um presumível «conhecimento», circunscrito à representação dos «factos» momentâneos (mesmo quando fidedigna). À míngua de remédio, ficamos sem remedeio encravados no lamaçal torço da imediatez existenciada.

Por isso, ao pensar filosófico igualmente incumbe empreender uma sondagem, e o desbravamento, do leque de possiveis - sobretudo, das possibilidades reais - que cada existência (internamente entretecida de negatividade) com-porta, e que ao adiante de si pro-jecta.

Não, para fazer carreira no ramo a que se dedicam as conceituadas indústrias da vidência profética. Não, para que a filosofia se reconverta num cosmopolita aeroporto espiritual de voos intercontinentais com aterragem feliz prometida nos impossíveis da «utopia» (que deseja tanto mais os «fins», quanto menos tem na devida conta os meios, e nem trabuca para os pôr de pé). Não, para desembocar na confecção magnífica de um «dever-ser» moral (que deixa intacta a materialidade do ser, satisfeito por lhe sobrepôr, em debrum, uma generosa ordem normativa de sonhos). Mas, para intentar compreender - e no limite: transformar (o que implica um empenhamento de energias práticas) - as realidades, no seu devir. As quais, na estadia do presente, não só trans-portam carregos do passado nas cafurnas, como aproam a um por vir em carência de materialização.

Esbocei por alto - olhando para baixo - alguns rasgos, que rasgam.

No seu conjunto, e por trajectórias diversas, todos estes traços permitem explicar que a filosofia - sem dúvida que nem sempre, mas já desde a sua primeva aparição na Grécia antiga como instituto cultural - tenha podido apresentar-se, umas vezes, como perigosa ameaça ao império indisputado das representações hegemónicas, e, amiúde, como um luminoso marcador de incomodidades generalizadas. Tudo por causa do trato que dispensa àquele indispensado interrogar molesto, que muita gente despede, mas de que ela não tem maneira de se despedir.

$\mathrm{Na}$ verdade da sua realidade, a filosofia - por vocação - é uma pro-vocação. Ao tirocínio do pensar.

Radical - no sentido que já Marx referia -, porque se alimenta de um descenso à raiz das coisas ${ }^{11}$. Para as sopesar, pesar, e repesar, na dialéctica materialidade dos seus procedimentos. Criticamente. Fundamentadamente. Problematizadamente. Com o sal da perspectiva. E dando sol à prospectiva.

11 «Ser radical é agarrar a coisa na raiz.» - «Radikal sein ist die Sache an der Wurzel fassen.», Marx, Zur Kritik der Hegelschen Rechtsphilosophie. Einleitung (1844); Marx-Engels Gesamtausgabe, ed. Günter Heyden e Anatoli Jegorow (MEGA2), Berlin, Dietz Verlag, 1982, vol. I/2, p. 177. 


\section{Dialéctica do compreender e do transformar}

Repete-se - pelo menos, desde um reparo de Platão ${ }^{12}$ e de Aristóteles ${ }^{13}$ - que a filosofia principia com «o admirar-se» (

Isso é certo. Se o entendermos bem, sobremaneira, no movimento que introduz.

Admirar-se não é infusão prolongada nos assombros da pasmaceira do basbaque. Com alguma agitação periférica, na quietude de um estupor conservado. A estranheza, a perplexidade, a discrepância, que se pressente - apanhadas na órbita do pensar - levam-nos a dar conta de que algo de «esquisito» se passa, pelo qual é preciso inquirir.

E é deste enfaixado feixe de perguntas em incoação, e em equacionamento, que arranca a estrada em que se palmilha o caminho de tornar as coisas inteligíveis.

A inteligibilidade não vem de repente. Tem curvas, contracurvas, e recurvos. Em rigor, ela somente se alcança mediante um «dar razão» $(\lambda o ́ \gamma o v \delta 1 \delta \text { óval })^{14}$. Necessita de que se venham a estabelecer determinadas conexões fundamentais.

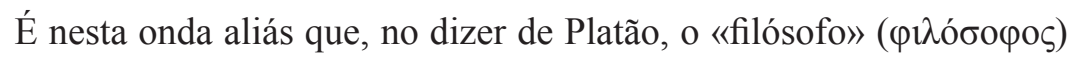

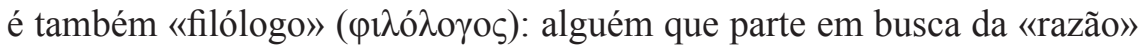

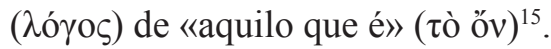

Todavia, na fidelidade ao preenchimento da sua missão vital, o pensar não pode ensimesmar-se nas delícias cogitativas do umbigo e dos seus arredores. Nem perfazer-se em parálise do agir. Nem esfarrapar-se num alibi pomposo para a renúncia ao nosso ofício de viventes.

Marx trazia carradas de razão na caixa aberta da camioneta, quando - castigando obediências filosóficas do seu tempo, e todas quantas, alhures, de achaques aparentados enfermem - descarrega: «Os filósofos têm apenas interpretado o mundo de diversas maneiras [verschieden]; trate-se de o transformar. $\rangle^{16}$.

Porém, ao arrepio de algumas hermenêuticas precipitadas - vulgares na praça, e vulgarizadas em compêndio -, por onde, acaso, deambula algum vestígio de remorso à cata de desobriga serôdia, entendo que esta sentença

12 Cf. Platão, Teeteto, $155 \mathrm{~d}$.

13 Cf. Aristóteles, Metafísica, A, 2, 982 b 12-13.

14 Cf. Platão, República, VII, 534 b.

15 Cf. Platão, República, IX, 582 e.

16 «Die Philosophen haben die Welt nur verschieden interpretiert, es kömmt drauf an, sie zu verändern.», Marx, Thesen über Feuerbach (1845), 11; MEW, vol. 3, p. 7. 
não configura um indiscriminado e peremptório decreto de expulsão a aplicar ao pensar filosófico sem mais tardança.

Pelo contrário. Na dança, há contradança.

Um dos resultados principais das Teses sobre Feuerbach, a meu ver, consiste, precisamente, em - pelo aclaramento crítico da «origem» dos desmandos perpetrados, e pela accionação consistente de um materialismo novo - recolocar a filosofia no seu posto. Que é também uma trincheira de combates.

Não é fatal que a filosofia tenha que ir desaguar a uma consagração apoteótica (espiritualmente assistida) das dominações vigentes em cada episódio. Como fatal não é também que a ordem instalada (um sistema organizado de desordens) seja, por desígnio superior da Providência, inelutável.

No horizonte dianteiro (e no miolo intestino) de uma crítica que praticamente transforma, não perde funcionalidade (e dinâmica) o desempenho necessário (porque lucífero) de uma crítica teórica. Ou seja: o esforço racional por «conceber» (begreifen) a realidade - nas suas contradições (as flagrantes, e as atabafadas), e no seu processo de desenvolvimento (que abre o passo à realização de possibilidades novas, materialmente fundadas).

A metafísica - submetida ao império daquele ressequido primado da identidade abstracta que lhe enclausura o intervalo, e tolhe a movimentação - não logra triunfar das antinomias: opõe a «teoria» à «prática», e a «prática» à «teoria». A dialéctica, porém, pensa o concreto enlace delas. Porque constitui a bacia vascularizada por onde irrompe, na história dos humanos, o pulsar mesmo do ser.

O apregoado poder das ideias não é discricionário, nem incircunscrito. Possui um limite material. Altera outras ideias. Por si, não transforma o mundo (a não ser, nas algazarras do pregão).

$\mathrm{E}$, na fronteira porosa destes tristes infortúnios, convém que se não esqueça: uma prática cega é o correlato confrangedor de uma teoria autista.

Na sua indeclinável premência, o desafio é, pois, outro:

Compreender para transformar, transformar compreendendo.

De ordinário, passa despercebido. Mas, na realidade, é de ontologia política que Lénine está a falar, quando, castigando a tentação oportunista em que certos activismos atarantados se estatelam, adverte: «Sem teoria revolucionária não pode haver também movimento revolucionário.» ${ }^{17}$

17 Vladímir Ilitch Lénine, Que fazer? Problemas candentes do nosso movimento (1902), I, d; Obras Escolhidas em Três Tomos, Lisboa - Moscovo, Edições Avante - Edições Progresso, 1977, vol. I, pp. 96-97. 


\section{Faz falta pensar}

Começámos o périplo da faladura pelas cumeadas rarefeitas do pensar filosófico. E acabamos por vir parar às «planices» do quotidiano chão.

Talvez, porque o pensar, sem os frumentos da vida, é um eixo ao rodopelo pela imensidão do vazio. E porque o pensamento, apesar de tudo, constitui uma ferramenta com préstimo nas carpintarias do nosso viver.

Faz falta pensar.

Até porque o desencorajamento a essa exercitação nos vem de mansinho soprado de não poucos quadrantes. É uma maçada, e só traz complicações...

Num mundo onde simulacros e aparências nos são diariamente servidos como a ementa que esgota o teor aguado das realidades sem encorpadura, urge ter «a coragem da verdade» (der Mut der Wahrheit). Como já Hegel sublinhava aos alunos, «a condição primeira» (die erste Bedingung) que o estudo filosófico exige ${ }^{18}$.

O temor reverencial pela «Verdade» que soletrada se acolhe (sem que mereça as canseiras de uma investigação) poderá ser treinado em cantos, e descantes, de madrassa. Mas a filosofia não é propriamente uma guitarrada para madraços assustadiços.

Partir em demanda do verdadeiro é uma autêntica expedição de escafandrismo pensante. Supõe um mergulho na materialidade dialéctica do ser. No seu enrugamento, nas suas relações retorsas, naquele encaixado surdir das contradições que a polarizam. Para surpreender a unidade (concreta) que ela forma, sem desperdiçar a multiplicidade (com estrutura) de que ela se tece e entretece.

Trata-se de um endereço incontornável, a cuja porta o pensar filosófico sempre acaba por ir bater.

São estes trajectos que Heraclito nos retrata, quando cuida de destacar:

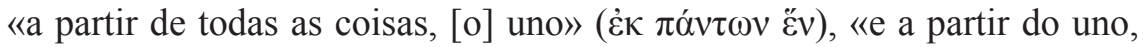

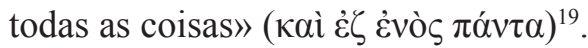

E, no que diz respeito ao tabuleiro complementar - em que as fainas se rebatem sobre quem as leva a cabo -, invocaria também, à saída, uma cutilada famosa.

18 Cf. Hegel, Konzept der Rede beim Antritt des philosophischen Lehramtes an der Universität Berlin. Einleitung zur Enzyklopädie-Vorlesung (1818); TW, vol. 10, p. 404.

${ }^{19}$ Heraclito, Fragmento B 10; Die Fragmente der Vorsokratiker, ed. Hermann Diels e Walther Kranz, Berlin, Weidmannsche Verlagsbuchhandlung, 19568, vol. I, p. 153. 
Nesta formulação, provém de Henri Bergson. Sendo recomendável, no entanto, fornecer-lhe um sortimento - ontológico, e prático acentuadamente distinto daquela peculiar mobília (idealista) que o autor lhe havia encomendado. E reza assim:

«É preciso agir como homem de pensamento, e pensar como homem de acção» ${ }^{20}$.

A frase é lapidária no sonante da soada. Mas não nos dispensa dos transpirados suores da lapidação trabalhada.

$\mathrm{O}$ viver, tal como o pensar - que nós apanhamos sempre na marcha, já com a composição em andamento -, des-equilibram ao feituro. São um permanente a-fazer do por fazer.

Sentir-me-ia gratificado, se as minhas palavras desta manhã - pobres, a despeito dos excessos na imodéstia - houvessem contribuído para o reforço de uma sensibilização ao grato empreender destas aventuras de descobrimento.

Muito obrigado, pela permanência paciente da vossa escuta.

Lisboa, Setembro de 2014.

${ }^{20}$ «Il faut agir en homme de pensée et penser en homme d'action», Henri Bergson, L'Académie Française vue de New York par un de ses membres (1935); Écrits et Paroles, ed. Rose-Marie Mossé-Bastide, Paris, Presses Universitaires de France, 1959, vol. III, p. 613. 